\title{
Monoclonal neutralizing antibodies against EV71 screened from mice immunized with yeast-produced virus-like particles
}

\author{
Tao Lin, Lingzhi Xianyu, Songya Lyu \\ State Key Laboratory of Virology, College of Life Sciences, Wuhan University, Wuhan 430072, China
}

Periodic outbreaks of hand, foot and mouth disease (HFMD) occur in children under 5 years old, and can cause death in some cases. The C4 strain of enterovirus 71 (EV71) is the main pathogen that causes HFMD in China. Although no drugs against EV71 are available, some studies have shown that candidate vaccines or viral capsid proteins can produce anti-EV71 immunity. In this study, female BABL/c mice (6-8 weeks old) were immunized with virus-like particles (VLPs) of EV71 produced in yeast to screen for anti-EV71 antibodies. Two hybridomas that could produce neutralizing antibodies against EV71 were obtained. Both neutralizing mAbs (D4 and G12) were confirmed to bind the VP1 capsid protein of EV71, and could protect $>95 \%$ cells from 100 TCID $_{50}$ EV71 infection at $25 \mu \mathrm{g} / \mathrm{mL}$ solution (lowest concentration). Those two neutralizing mAbs identified in the study may be promising candidates in development for mAbs to treat EV71 infection, and utilized as suitable reagents for use in diagnostic tests and biological studies.

KEYWORDS hand, foot and mouth disease; enterovirus 71 (EV71); virus-like particles (VLPs); hybridoma; neutralizing antibodies

\section{INTRODUCTION}

Hand, foot and mouth disease (HFMD) is an infectious disease that has shown outbreaks in the Asia-Pacific region in recent years, especially in mainland China (Ho et al., 1999; Fujimoto et al., 2002; Singh et al., 2002; Baek et al., 2009; Zhang et al., 2009; Chatproedprai et al., 2010). HFMD often occurs in children under the age of five, causing mouth pain, loss of appetite, fever, and sores or ulcers in patients' hands, feet and mouths; it can cause neurological complications in some cases (Lee et al., 2009). Severe progression of HFMD can lead to death (Chonmaitree et al., 1981). HFMD is caused by 20 types of enteroviruses; enterovirus 71 (EV71) is the most common pathogen (Lee et al., 2009; Wong et al., 2010). EV71 belongs to the enterovirus group of the family

Received: 14 February 2015, Accepted: 11 May 2015

Published online: 29 May 2015

$\triangle$ Correspondence:

Phone: +86-27-68752043, Fax: +86-27-68752043,

Email:00006510@whu.edu.cn

ORCID: 0000-0001-7472-0260
Picornaviridae (Wong et al., 2010).

No effective therapeutic approaches or vaccines against HFMD are currently available. Live virus (Chang et al., 2011), inactivated virus (Chang et al., 2010), and recombinant VP1 protein (Wu et al., 2001; Chen et al., 2006; Sivasamugham et al., 2006; Chen et al., 2008; Li et al., 2009; Zhou et al., 2015) have been used to produce anti-EV71 antibodies. EV71 virus-like particles (VLP) are hollow viral particles that contain only the capsid proteins (VP0, VP1, and VP3) but lack viral nucleic acids, and which cannot replicate autonomously (Liu et al., 2011). VLPs are a new type of immunogen that can be used to develop antiviral antibodies (Roldao et al., 2010; Li et al., 2013); they possess complete epitopes, but are much safer than inactivated virus or viral proteins alone.

In this study, highly purified EV71-VLPs produced in yeast were used to immunize mice to generate hybridomas for screening anti-EV71 antibodies. Two hybridomas, which produced antibodies that could effectively bind to EV71 were identified. Furthermore, the antiviral capability of those two monoclonal neutralizing antibodies was evaluated. 


\section{MATERIALS AND METHODS}

\section{Antigens, immunization of mice, and hybridoma generation}

The EV71-VLPs were produced in yeast and were provided by Shanghai Zerun Biotech Co., Ltd (Shanghai, China). The female BALB/c mice (aged 6-8 weeks) used in the immunization experiments were purchased from the Hubei Provincial Center for Disease Control and Prevention. One group of three mice was immunized subcutaneously with $20 \mu \mathrm{g}$ of EV71-VLPs mixed with an equal volume of complete or incomplete Freund's adjuvant (for primary and booster injections, respectively) at weeks 0,2 , and 4 . Blood samples from each mouse were collected from the tail artery at week 6 and their capacity to bind EV71 was determined through ELISA. The mouse with the highest titer was boosted with a double dose at week 6. Splenocytes were isolated from this mouse and fused with $\mathrm{SP}_{2 / 0}$ myeloma using PEG solution to generate hybridomas. After two weeks, hybridoma cells that could produce EV71-specific antibodies were screened by ELISA. Briefly, $20 \mathrm{ng}$ of inactivated EV71 virus was coated on 96-well ELISA plates and incubated overnight at $4{ }^{\circ} \mathrm{C}$. Then the plates were washed with PBST three times, incubated with $100 \mu \mathrm{L}$ of PBST containing 5\% non-fat milk for $1 \mathrm{~h}$, washed with PBST three times, incubated with $100 \mu \mathrm{L}$ of hybridoma culture supernatant for $1 \mathrm{~h}$, washed with PBST three times, incubated with 100 $\mu \mathrm{L}$ of anti-mouse IgG secondary antibodies conjugated with horseradish peroxidase for $1 \mathrm{~h}$, washed with PBST three times, and incubated with $100 \mu \mathrm{L}$ of chemiluminescent substrate. After color development, the reaction was stopped by addition of $100 \mu \mathrm{L}$ of $2 \mathrm{mmol} / \mathrm{L} \mathrm{H}_{2} \mathrm{SO}_{4}$ and the absorbance was measured at $450 \mathrm{~nm}$.

\section{Cells, culture medium, and viruses}

Human rhabdomyosarcoma (RD) cells were cultured in DMEM (Dulbecco Modified Eagle Medium) supplemented with $100 \mathrm{~mL} / \mathrm{L}$ fetal bovine serum (FBS, Gibco BRL), $100 \mu \mathrm{g} / \mathrm{mL}$ of penicillin, and $100 \mu \mathrm{g} / \mathrm{mL}$ of streptomycin. $\mathrm{SP}_{2 / 0}$ cells were cultured in RPMI-1640 medium supplemented with $10 \% \mathrm{FBS}, 100 \mu \mathrm{g} / \mathrm{mL}$ of penicillin and $100 \mu \mathrm{g} / \mathrm{mL}$ of streptomycin. Hybridoma cells were cultured in RPMI-1640 medium supplemented with $10 \%$ FBS, $100 \mu \mathrm{g} / \mathrm{mL}$ of penicillin, $100 \mu \mathrm{g} / \mathrm{mL}$ streptomycin, and HAT supplement (50×). The titers of EV71 strain C4 (China Center for Type Culture Collection (CCTCC) No. GDV103, PopSet No. KC954663.1) were determined using RD cells, which were expressed as the $50 \%$ tissue culture infectious dose $\left(\mathrm{TCID}_{50}\right)$, according to the Karber method.

\section{Antibody purification}

Antibodies were purified from cell culture superna- tants using Protein $\mathrm{A}+\mathrm{G}$ Sepharose ${ }^{\mathrm{TM}}$ (GE Healthcare), according to the manufacturer's instructions.

\section{Characterization of purified antibodies by ELISA}

Concentrations of proteins or antibodies were measured by the Bradford method. Twenty nanograms of VP1 protein, inactivated EV71 virus, or PBS were coated on 96-well ELISA plates and incubated overnight at $4{ }^{\circ} \mathrm{C}$. Purified mAbs $(0.5 \mu \mathrm{g} /$ well $)$ were applied and incubated at $37{ }^{\circ} \mathrm{C}$ for $1 \mathrm{~h}$, followed by administration of an anti-mouse IgG secondary antibody and the chemiluminescent substrate. Finally, the absorbance was measured at $450 \mathrm{~nm}$.

\section{SDS-PAGE and Western blot}

Proteins samples $(5 \mu \mathrm{g}$ of VLPs, $10 \mu \mathrm{g}$ of purified $\mathrm{mAb}$, or $5 \mu \mathrm{g}$ of inactivated EV71 virus) were loaded into a $10 \%$ SDS-polyacrylamide gel for electrophoresis. Samples were stained with Coomassie blue or transferred to PVDF membrane. For Western blot analysis, the membrane was successively immersed in $5 \% \mathrm{BSA}$ at $4{ }^{\circ} \mathrm{C}$, incubated for $1 \mathrm{~h}$ with purified $\mathrm{mAbs}(1.6 \mathrm{mg} / \mathrm{mL})$ or a VP1-specific antiserum, washed with TBST three times, incubated with anti-mouse IgG secondary antibodies conjugated with horseradish peroxidase, and washed in TBST a further three times. Finally, the proteins were visualized using SuperSignal West Pico Chemiluminescent Substrate.

\section{Neutralization assay}

The neutralization concentration of purified mAb (1.6 $\mathrm{mg} / \mathrm{mL}$ ) was determined using a plaque reduction assay and a TCID $_{50}$ reduction assay in RD cells. RD cells were cultured in 96-well plates overnight until $70 \%$ confluence. Antibodies were serially diluted two-fold with DMEM containing 2\% FBS. One hundred microliters of EV71 virus containing $100 \mathrm{TCID}_{50}$ was mixed with 100 $\mu \mathrm{L}$ of diluted $\mathrm{mAb}$. After incubation at $37^{\circ} \mathrm{C}$ for $1 \mathrm{~h}$, the mixtures were added to the RD cells. After 6 days of culture, the lowest neutralization concentration was evaluated by observing the appearance of cytopathic effects (CPE).

\section{RESULTS}

\section{Characterization of EV71-VLPs produced in yeast}

The physical structure of the EV71-VLPs was determined using transmission electron microscope (TEM) analysis at the instrument center of the College of Life Sciences, Wuhan University. TEM images of negatively stained samples showed the presence of intact VLPs (Figure 1A), which had an icosahedral structure and which were morphologically similar to EV71 virus par- 

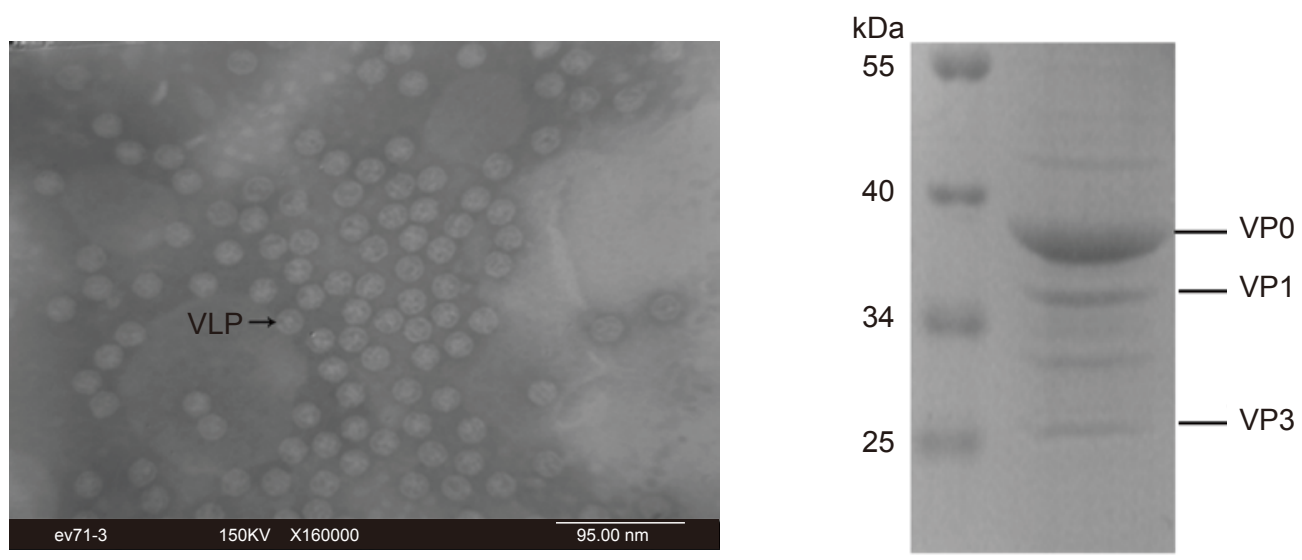

Figure 1. Virus-like particles were characterized using TEM examination (A) and SDS-PAGE (B). (A) Images of VLPs were analyzed by TEM at 160,000x magnification. The VLPs were approximately $30 \mathrm{~nm}$ in diameter and were morphologically similar to empty particles of EV71. (B) SDS-PAGE assay demonstrated the presence of three EV71 capsid proteins (5 $\mu \mathrm{g}$ VLPs): VP0 (38 kDa), VP1 (36 kDa), and VP3 (27 kDa) in the VLPs.

A

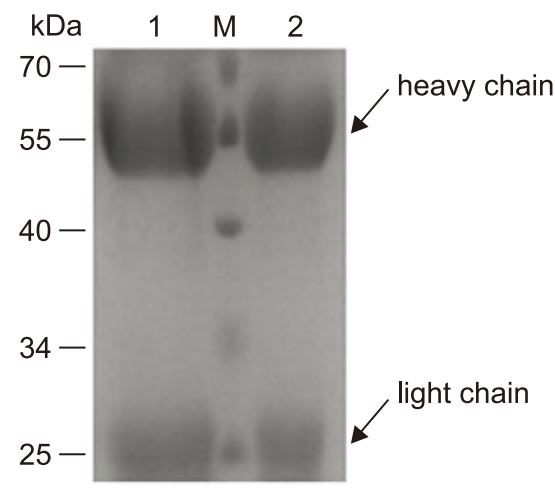

B

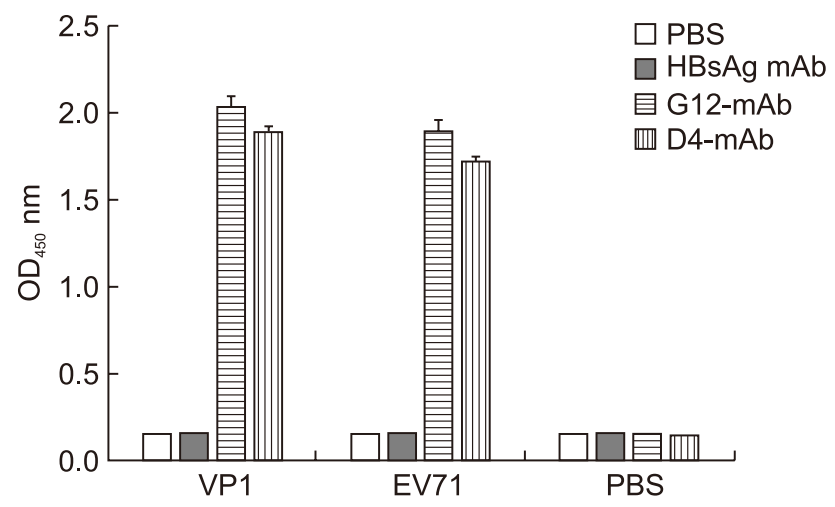

C
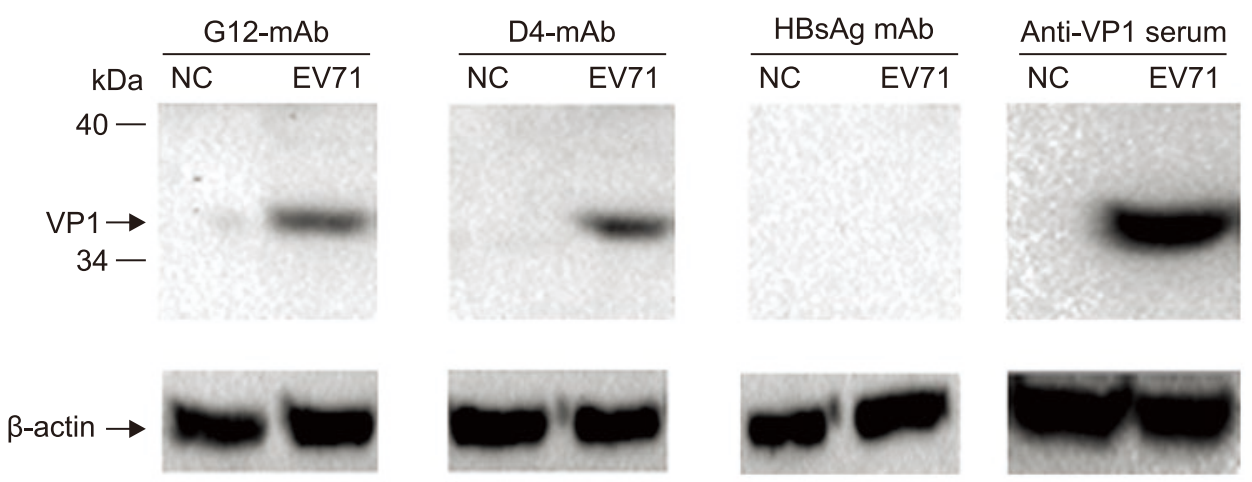

Figure 2. Relative titer of $m A b s$ reacted with different antigens and specificity testing of mAbs. (A) The purified antiEV71 antibodies (10 $\mu \mathrm{g}$ per lane) were analyzed by SDS-PAGE. Lane M, protein size standards; Lane 1, mAb from G12 hybridoma cells (mAb G12); lane 2, antibodies from D4 hybridoma cells (mAb D4). (B) Triplicate samples (20 ng/well of VP1 protein, inactivated EV71 virus, or PBS) were added to a 96-well ELISA plate. Purified antibody $(0.5 \mu \mathrm{g} /$ well $)$ was applied and incubated at $37{ }^{\circ} \mathrm{C}$ for $1 \mathrm{~h}$, followed by an anti-mouse lgG secondary antibody. Anti-HBsAg mAb and PBS were used as the negative control and the blank control, respectively. The average $\mathrm{OD}_{450} \pm$ standard showed the relative titer. (C) Five micrograms of inactivated EV71 virus was resolved using a $10 \%$ SDS-PAGE gel, followed transfer to a PVDF membrane, probing with mAb D4, G12, HBsAg mAb, or VP1specific antiserum and incubated with anti-mouse lgG horseradish peroxidase-conjugated secondary antibodies. Uninfected RD cells were used as the negative control. 
ticles (Wang et al., 2012). The SDS-PAGE assay showed the presence of three major structural proteins, VP0 (38 $\mathrm{kDa}), \mathrm{VP} 1(36 \mathrm{kDa})$, and VP3 (27 kDa), of EV71 in the VLPs (Figure 1B). Thus, VLPs produced in yeast are of good quality and can be used as immunogens.

\section{Screening of hybridomas that secrete anti-EV71 antibodies}

The supernatant of the hybridoma cell culture was assayed by ELISA to evaluate its ability to bind to inactivated EV71 virus. The neutralization capacity of the positive supernatants was determined by an in vitro neutralization assay. Following four rounds of ELISA and neutralization assay screening, two hybridomas (D4 and G12) that could produce anti-EV71 antibodies that showed a strong reaction with the above antigens and that could effectively inhibit EV71 infection were identified.

\section{Purity, titer, and specificity of anti-EV71 antibodies}

The purity and integrity of the antibodies that were purified from the supernatant of the hybridoma D4 or G12 cell cultures with protein $\mathrm{A}+\mathrm{G}$ Sepharose ${ }^{\mathrm{TM}}$ were analyzed by SDS-PAGE. The heavy chain $(55 \mathrm{kDa})$ and light chain $(25 \mathrm{kDa})$ molecules of both antibodies (mAb D4 and G12) were as expected (Figure 2A, lanes 1 and 2).

The D4 and G12 mAbs were then analyzed with ELISA to determine their relative titers with different antigens (VP1 protein, inactivated EV71 virus, or PBS). As shown in Figure 2B, both purified mAbs reacted with the VP1 protein and the inactivated EV71 virus, but the anti-HBsAg negative control and the PBS blank control showed no significant reactivity with the antigens.

The specificity of the D4 and G12 mAbs were evaluated by Western blot analysis. Comparison of VP1-specific antiserum with control anti-HBsAg showed that both purified mAbs could react with VP1 of EV71 positively and specifically (Figure 2C).

\section{Neutralizing effect of anti-EV71 D4 and G12 mAbs}

The neutralizing effect of the purified antibodies was tested using an in vitro neutralization assay. EV71 (100 $\mathrm{TCID}_{50}$ ) was incubated with serially diluted antibodies, followed by infection of RD cells. Uninfected RD cells were used as negative controls and infected RD cells with PBS were used as positive controls. As shown in Table 1, the lowest $\mathrm{mAb}$ concentration that could protect $>95 \%$ cells from CPE was $25 \mu \mathrm{g} / \mathrm{mL}$. In contrast, RD cells infected with the virus alone showed severe CPE that resulted in cell rounding, aggregation, and flotation (Figure 3A).

Uninfected RD cells grew normally (Figure 3B). As shown by the plaque reduction and $\mathrm{TCID}_{50}$ assays, pre-
Table 1. Neutralization capacity of purified mAbs to inhibit CPE

\begin{tabular}{lcc}
\hline $\mathrm{mAb}$ concentration $(\mu \mathrm{g} / \mathrm{mL})$ & $\mathrm{D} 4$ & $\mathrm{G} 12$ \\
\hline 1600 & + & + \\
800 & + & + \\
400 & + & + \\
200 & + & + \\
100 & + & + \\
50 & + & + \\
25 & + & + \\
12.5 & - & - \\
6.25 & - & - \\
\hline "+" indicates mAbs could protect $>$ 95\% of cells from EV71 \\
infection; lack of protection is shown as “-”
\end{tabular}
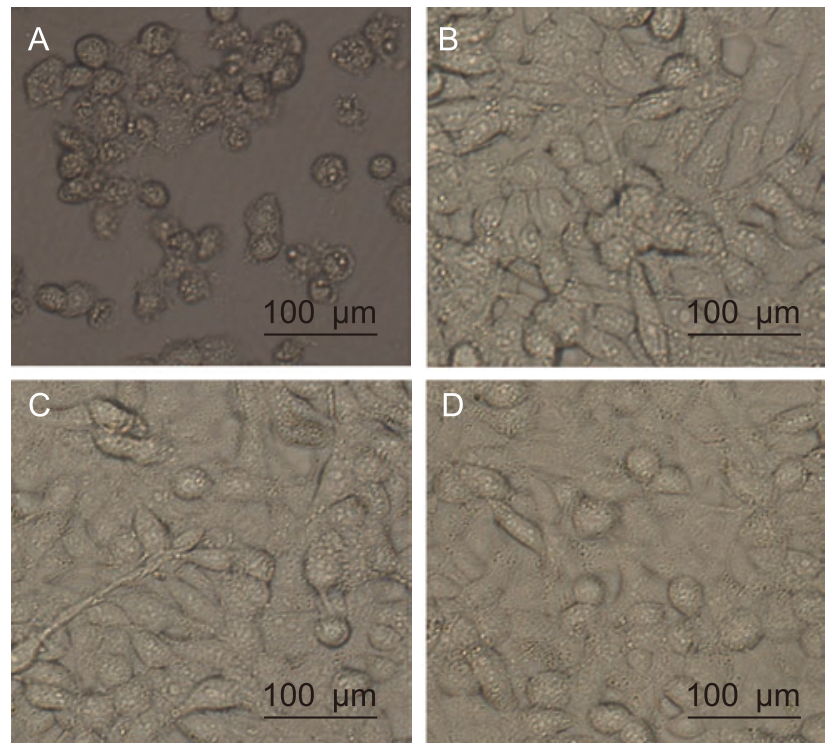

Figure 3. Effect of mAbs treatment on EV71-induced $\mathrm{CPE}$. Cells were photographed at 6 days post-infection. (A) Infected RD cells incubated with PBS. (B) Uninfected RD cells. (C) pretreated EV71 with $25 \mu \mathrm{g} / \mathrm{mL}$ of $\mathrm{mAb}$ G12. (D) Pretreated EV71 with $25 \mu \mathrm{g} / \mathrm{mL}$ of $\mathrm{mAb}$ D4.

treatment of the virus with the lowest concentration anti-EV71 antibodies ( $25 \mu \mathrm{g} / \mathrm{mL}$ of G12 or D4) protected $>95 \%$ of cells from CPE development (Figure $3 \mathrm{C}, \mathrm{mAb}$ G12; Figure 3D, mAb D4). Thus, the two purified antibodies have EV71-neutralizing effects.

\section{DISCUSSION}

Neutralizing antibodies against EV71 have been produced in mice immunized with live virus (Chang et al., 2011), inactivated virus (Chang et al., 2010), or recombinant VP1 protein (Wu et al., 2001; Chen et al., 2006; Sivasamugham et al., 2006; Chen et al., 2008; Li et al., 
2009; Zhou et al., 2015). Live or inactivated virus can produce a high level of immunogenicity and protection. However, the safety of these treatments is controversial. Although the immunogenicity of recombinant VP1 protein is limited, due to a lack of sufficient epitopes, SP70 (VP1 208-222 aa) produces effective antibodies against EV71 but with a low neutralizing titer.

Virus-like particles (VLPs) are composed of viral capsid proteins, but lack the complete virus genome. VLPs have the same morphology and structure as viral capsid proteins. The immunogenicity of VLPs is usually similar to that of the live or inactivated virus but stronger than that of a single viral protein; their safety is as high as that of single protein antigens. Therefore, VLPs have become a crucial material for development of therapeutic approaches and vaccines against viruses (Roldao et al., 2010). Li et al. (2013) reported that EV71-VLPs, which were produced by expressing the $\mathrm{P} 1$ and $3 \mathrm{CD}$ proteins in a yeast cell expression system, could efficiently induce robust humoral and cellular responses in mice. IgG titer and cytokine (IFN- $\gamma$, IL-2, IL-4, and IL-6) levels were significantly increased. In addition, serum from immunized mice appeared to neutralize EV71.

In our study, we used highly purified EV71-VLPs generated in yeast to stimulate mice for screening of neutralizing antibodies against EV71. Both ELISA and Western blot analyses showed that the neutralizing antibodies secreted from two strains of hybridoma cells $(\mathrm{G} 12, \mathrm{D} 4)$ could effectively recognize EV71 capsid proteins and showed anti-EV71 capacity. Both antibodies could protect $>95 \%$ of cells from 100 TCID $_{50}$ EV71 infection in $25 \mu \mathrm{g} / \mathrm{mL}$ solution. The results demonstrated that VLPs of EV71 can elicit the production of neutralizing antibodies in mice, and those two neutralizing mAbs may be promising candidates in development for $\mathrm{mAbs}$ to treat EV71 infection, and utilized as suitable reagents for use in diagnostic tests and biological studies.

\section{ACKNOWLEDGMENTS}

This research has been supported by the grant from National Natural Science Foundation of China (No.31070147).

\section{COMPLIANCE WITH ETHICS GUIDELINES}

The authors declare that they have no conflict of interest. The whole study was approved by the ethics committee of the College of Life Sciences, Wuhan University, China (No.WDSKY0201303).

\section{AUTHOR CONTRIBUTIONS}

SY Lyu and T Lin designed the experiments. T Lin performed the experiments. SY Lyu, T Lin and LZ Xianyu analyzed the data. SY Lyu and T Lin wrote the paper. All authors have read and approved the final manuscript.

\section{REFERENCES}

Baek K, Park K, Jung E, Chung E, Park J, Choi H, Baek S, Jee Y, Cheon D, Ahn G. 2009. Molecular and epidemiological characterization of enteroviruses isolated in Chungnam, Korea from 2005 to 2006. J Microbiol Biotechnol, 19: 1055-1064.

Chang GH, Luo YJ, Wu XY, Si BY, Lin L, Zhu QY. 2010. Monoclonal antibody induced with inactived EV71-Hn2 virus protects mice against lethal EV71-Hn2 virus infection. Virol J, 7: 106.

Chang HW, Liu CC, Lin MH, Ho HM, Yang YT, Chow YH, Chong P, Sia C. 2011. Generation of murine monoclonal antibodies which cross-neutralize human enterovirus genogroup $\mathrm{B}$ isolates. J Virol Methods, 173: 189-195.

Chatproedprai S, Theanboonlers A, Korkong S, Thongmee C, Wananukul S, Poovorawan Y. 2010. Clinical and molecular characterization of hand-foot-and-mouth disease in Thailand, 2008-2009. Jpn J Infect Dis, 63: 229-233.

Chen HF, Chang MH, Chiang BL, Jeng ST. 2006. Oral immunization of mice using transgenic tomato fruit expressing VP1 protein from enterovirus 71. Vaccine, 24: 2944-2951.

Chen HL, Huang JY, Chu TW, Tsai TC, Hung CM, Lin CC, Liu FC, Wang LC, Chen YJ, Lin MF, Chen CM. 2008. Expression of VP1 protein in the milk of transgenic mice: a potential oral vaccine protects against enterovirus 71 infection. Vaccine, 26: 2882-2889.

Chonmaitree T, Menegus MA, Schervish-Swierkosz EM, Schwalenstocker E. 1981. Enterovirus 71 infection: report of an outbreak with two cases of paralysis and a review of the literature. Pediatrics, 67: 489-493.

Fujimoto T, Chikahira M, Yoshida S, Ebira H, Hasegawa A, Totsuka A, Nishio O. 2002. Outbreak of central nervous system disease associated with hand, foot, and mouth disease in Japan during the summer of 2000: detection and molecular epidemiology of enterovirus 71. Microbiol Immunol, 46: 621-627.

Ho M, Chen ER, Hsu KH, Twu SJ, Chen KT, Tsai SF, Wang JR, Shih SR. 1999. An epidemic of enterovirus 71 infection in Taiwan. Taiwan Enterovirus Epidemic Working Group. N Engl J Med, 341: 929-935.

Lee TC, Guo HR, Su HJ, Yang YC, Chang HL, Chen KT. 2009. Diseases caused by enterovirus 71 infection. Pediatr Infect Dis J, 28: 904-910.

Li HY, Han JF, Qin CF, Chen R. 2013. Virus-like particles for enterovirus 71 produced from Saccharomyces cerevisiae potently elicits protective immune responses in mice. Vaccine, 31: 3281-3287.

Li X, Mao C, Ma S, Wang X, Sun Z, Yi Y, Guo M, Shen X, Sun L, Bi S. 2009. Generation of neutralizing monoclonal antibodies against Enterovirus 71 using synthetic peptides. Biochem Biophys Res Commun, 390: 1126-1128.

Liu CC, Guo MS, Lin FH, Hsiao KN, Chang KH, Chou AH, Wang YC, Chen YC, Yang CS, Chong PC. 2011. Purification and characterization of enterovirus 71 viral particles produced from vero cells grown in a serum-free microcarrier bioreactor system. PLoS One, 6: e20005.

Roldao A, Mellado MC, Castilho LR, Carrondo MJ, Alves PM. 2010. Virus-like particles in vaccine development. Expert Rev Vaccines, 9: 1149-1176.

Singh S, Chow VT, Phoon MC, Chan KP, Poh CL. 2002. Direct 
detection of enterovirus 71 (EV71) in clinical specimens from a hand, foot, and mouth disease outbreak in Singapore by reverse transcription-PCR with universal enterovirus and EV71-specific primers. J Clin Microbiol, 40: 2823-2827.

Sivasamugham LA, Cardosa MJ, Tan WS, Yusoff K. 2006. Recombinant Newcastle Disease virus capsids displaying enterovirus 71 VP1 fragment induce a strong immune response in rabbits. J Med Virol, 78: 1096-1104.

Wang X, Peng W, Ren J, Hu Z, Xu J, Lou Z, Li X, Yin W, Shen X, Porta C, Walter TS, Evans G, Axford D, Owen R, Rowlands DJ, Wang J, Stuart DI, Fry EE, Rao Z. 2012. A sensor-adaptor mechanism for enterovirus uncoating from structures of EV71. Nat Struct Mol Biol, 19: 424-429.

Wong SS, Yip CC, Lau SK, Yuen KY. 2010. Human enterovirus
71 and hand, foot and mouth disease. Epidemiol Infect, 138: 1071-1089.

Wu CN, Lin YC, Fann C, Liao NS, Shih SR, Ho MS. 2001. Protection against lethal enterovirus 71 infection in newborn mice by passive immunization with subunit VP1 vaccines and inactivated virus. Vaccine, 20: 895-904.

Zhang Y, Tan XJ, Wang HY, Yan DM, Zhu SL, Wang DY, Ji F, Wang XJ, Gao YJ, Chen L, An HQ, Li DX, Wang SW, Xu AQ, Wang ZJ, Xu WB. 2009. An outbreak of hand, foot, and mouth disease associated with subgenotype $\mathrm{C} 4$ of human enterovirus 71 in Shandong, China. J Clin Virol, 44: 262-267.

Zhou SL, Ying XL, Han X, Sun XX, Jin Q, Yang F. 2015. Characterization of the enterovirus 71 VP1 protein as a vaccine candidate. J Med Virol, 87: 256-262. 